\title{
A new numerical method applied to the study of mass oscillations in a pumped storage hydro-electric scheme
}

\author{
G. D. MATTHEW \& J. F. ROBBIE
}

\section{Mr R. J. T. Casinader, Binnie and Partners}

Methods previously suggested for numerical or graphical solution of the problem of mass oscillations in hydraulic surge systems have, for all real cases, been in one form or another step-by-step integration procedures. The new method now proposed by the Authors breaks no new ground in this respect. While accepting that the governing equations can only be solved in closed analytical form for a limited number of cases, I still hope that a more elegant method will some day be devised for dealing with the problem. The refinement of the extrapolation technique proposed by the Authors is, however, a notable contribution to the subject.

52. The digital computer has, as the Authors mention, been used in conjunction with simple step-by-step integration methods, its main advantage being the facility of using smaller step sizes than would normally be used in hand or graphical computations. The limitation is of course the onset of instability as the step size is reduced, that is, instability in the computations rather than the actual surge. The Authors' method is designed from the outset to avoid this instability at each step. However, it should be possible when using a digital computer with a simple step-bystep method, say the Heun method, to carry out successive runs using smaller and smaller step sizes until instability is induced. One or two such runs on any system should indicate the smallest step size that should be employed to obtain reasonable accuracy without inducing instability in the computations. The method is, in effect, to apply the equivalent of the Authors' convergence, or accuracy, test and divergence test to the whole calculation rather than to each step.

53. The Authors' views on the merits of this procedure relative to those of the method they propose would be of interest, bearing in mind the relative computational costs of each method. The simpler method should be suitable for the analysis of much more complicated surge systems than that analysed by the Authors. Would the Authors' method be equally suitable for dealing with systems of, say, two or more surge tanks?

54. The new method has apparently been devised specifically for dealing with surges in pumped storage hydro-electric systems. Such systems have particular characteristics, which, although not exclusive to pumped storage schemes, have a bearing on the most suitable method of analysis. The schemes are generally high head with relatively short headrace and/or tailrace tunnels of large cross section. Friction losses are therefore relatively low. Surges in such systems have the following general characteristics:

(a) amplitudes are low relative to total head on the system;

(b) the period of the oscillations is short;

(c) damping of the oscillations is poor.

55. The significance of $(a)$ is that, as found at Cruachan, the amplitude of the surges is unlikely to affect machine governing appreciably. Under these circumstances accurate determination of the initial surge is only of importance to assess the adequacy of the system layout, e.g. the roof level of the surge chamber or the level

Paper published: Proc. Instn civ. Engrs, 1968, 41 (Nov.) 499-521. 
of the turbine/pump setting. The significance of $(c)$ is that dangerous superposition of surges may arise owing to stopping and starting of the machines. This is especially important in pumped storage installations where relatively frequent changes in operation can occur, and the accurate determination of the surge pattern over a considerable number of oscillations is therefore required.

56. Comparison of observed surges with those calculated by the Authors' method and shown in Fig. 11 shows good agreement for the later oscillations, and to this extent the method seems to be well suited to pumped storage systems. Agreement during the initial surge is, however, poor and the Authors' comments on this would be of value.

57. I would also like to draw attention to another characteristic of pumped storage installations which may have a bearing on the method used for analysing surges. Although the headrace and/or tailrace tunnels are generally much shorter than in conventional schemes, this is not the case with penstock and draft tube lengths, which are substantially the same as in conventional schemes. Penstock/ draft tube inertia and friction loss may therefore be significant in pumped storage systems. Is the method proposed by the Authors suitable for taking this factor into account?

58. Referring again to Fig. 11, no doubt the Authors would have noticed that, as printed, cases $(a)$ and $(b)$ described in the title of the figure and $\$ 47$ do not agree. They will presumably clarify this in their further comments, but it would seem that case (a) represents a 3-machine generation trip from 3400 cusecs and not a four-pump closure from 4300 cusecs. The surge shaft water level observed after about $20 \mathrm{~s}$ in this case is very much lower than the calculated value. The observed points suggested an initial sharp 'peak' followed by a broader 'peak'. Similar behaviour was obtained in the early investigations of a surge shaft with an expansion chamber with which I was concerned. The cause was found to be that an abrupt junction between the expansion chamber and shaft constituted a control section which prevented the water level in the expansion chamber falling at the same rate as that in the shaft. The remedy was a more gradual junction. Could there be a similar explanation for the behaviour observed at Cruachan?

\section{Mr E. P. Evans, Sir Alexander Gibb and Partners}

There is one point in the Paper which puzzles me. In $\S 39(a)$ the Authors state that it has been established that a simple method like that of Heun cannot itself produce an acceptable accuracy, even permitting unlimited subdivision. This appears to run counter to the proposition stated in equation (16) which is basic to the HeunRomberg method, namely

$$
\lim _{k \rightarrow \infty}\left\{X_{i+1}^{(k)}\right\}=X_{i+1}
$$

60. I assume that the practical effect of rounding is the limiting factor in the simple method, rather than anything more fundamental, but I would be glad of the Authors' amplification and comment on this point.

Dr C. Jaeger, Former Visiting Professor, Imperial College, Consultant to English Electric Co.

It is worthwhile examining this very interesting Paper in connexion with some other relevant publications.

62. In Fig. 11 the Authors reproduce mass oscillation curves for the Cruachan pumped storage scheme for $(a)$ sudden closure of all four pumps from steady discharge of 4300 cusec; (b) loss of power with all four machines pumping, followed by complete reversal of flow and runaway of the machines as turbines. These are two cases of extreme severity. In the first case, there is no governor action at all. In the 
second case, it can reasonably be assumed that the governor action can, at least to a first approximation, be neglected.

63. In all normal cases the turbines are provided with a governor, and whatever the degree of accuracy of the mathematical method used for integration, the physical importance of a governor cannot be ignored.

64. A governor tends, indirectly, to maintain constant the power generated by the turbines. A third equation

$$
P=\eta \gamma Q(H+Z) \quad \cdot \quad \cdot \quad \cdot \quad \cdot \quad . \quad . \quad .
$$

must be added to equations (1) and (2) mentioned by the Authors. In this equation $H$ is the gross head on the tubine, $Z$ is the elevation of water surface in the surge chamber above that in the reservoir (which here may be an upstream reservoir), $\gamma$ is the specific weight of the water and $\eta$ the efficiency of the turbines and generators. It is well known that this third equation adds to the complexity of the mathematical treatment. A vast literature deals with this subject. ${ }^{11}$

65. It is most probable that the mathematical methods developed by the Authors could be extended to this more difficult case too. Streeter ${ }^{12}$ develops some simple equations which most probably could also be extended to the case when there is a governor on the turbines. The equations (1), (2) and (3a) can also be solved on an analogue computer.

66. Most authors dealing with theories including an equation of the type of (3a) assume that the turbine efficiency is constant or can be represented by a simple mathematical law. It is doubtful whether such simplified assumptions are acceptable, and this point requires further investigation.

67. It is not possible to introduce the true law of $\eta$, depending on gate opening and the head variations, without calculating the true pressure at the turbine end. The surge equations fail to give this required information and water hammer methods must be used.

68. In an early publication ${ }^{13}$ it has been suggested that the water hammer equations could be used for calculating surge levels in surge tanks, when correctly writing the elastic wave equations for the pressure pipe line, the surge shaft and the long tunnel. This suggestion could not be checked before large computers were available, because of the very small time intervals (equal to the basic wave period of the surge shaft) which have to be used for the calculation.

69. It has now been proved that the water hammer method and the surge equations yield the same numerical results, provided that the same boundary conditions are introduced for both methods.

70. With the introduction of the water hammer equations in surge calculations, a far more powerful method of investigation is available than with the surge equations. For example, all variations of the conduit diameters and conduit bifurcations can be considered.

71. The result of detailed investigations has shown that the true value of the efficiency factor is, at least for some modern (reversible) turbines, very important and influences the surge levels in the tank.

72. There will be a tendency in future research to use the wave equations (water hammer) instead of the mass equations (surge equations) and it will be important to choose the wave method for writing programs. It is most probable that the Heun or the Heun-Romberg methods can be adapted to this problem.

73. A Symposium on Water Hammer in Pumped Storage Projects was organized by the Fluid Transient Committee of the Fluid Engineering Division of the American Society of Mechanical Engineers in Chicago (7-11 November, 1965), where similar methods have been submitted. M. Marchal, G. Flasch and P. Suter ${ }^{14}$ have developed a method which introduces reflexion functions of the type introduced in the early theories of water hammer. ${ }^{13}$ Streeter uses the very powerful and versatile "method of characteristics' and Wylie studies resonance problems with an 'impedance 
method'.12,15.18 Considerable progress has been achieved in research on surges and shocks with these methods.

74. A final, very difficult problem is still to be investigated, namely the reactions between the hydraulic system and the electric distribution system in which the hydroelectric power stations are integrated. It is likely that some basic design rules for the large surge tanks (Thoma's criterion ${ }^{16}$ ) could be modified if the effects of system integration could be correctly analysed.

75. If we are well informed, such an investigation has been carried out for a very large system using the methods of analogue computers.

76. In recent years the interest of research has therefore shifted from simple surge problems to stability problems, and the Heun-Romberg methods could possibly be used in that direction too.

\section{Mr R. W. Buchanan, James Williamson and Partners}

The use of the digital computer in the solution of surge problems such as described by the Authors is now accepted practice, and it may be useful to consider briefly its relation to other design tools available to the engineer.

78. The development of the design of a scheme such as Cruachan may well extend over a decade, and during that time many tentative layouts and surge shaft designs will have been considered. In the early stages a slide rule and a design chart may give the engineer all the answers he requires. Even if and when every design office is "on-line" to a computer, there will still be a place for manual computations of this type, and the function of the computer here is perhaps to aid in the preparation of design charts covering a wider range of surge problems than can at present be considered.

79. Once the design of the scheme as a whole is generally established, it has been usual in the past to resort to detailed step-by-step analysis of the surge chamber, either arithmetically or by some graphical procedure. These methods have been well proved in practice, and I think too much can be made of the tedium involved in such iterative computations. An experienced designer can produce a solution to a straightforward surge problem in a matter of hours, and if the total time spent on the development of the design of a surge shaft were analysed, the actual time spent on the step-by-step calculations would come out as a relatively small proportion. However, it is I think clear that this stage of surge shaft design will soon be passed wholly to the computer, the great advantage being that a wider range of variation of the various parameters can be considered without difficulty.

80. The construction of a hydraulic model as a check on computation is not generally justified for simple surge systems, but for more complicated problems, as at Cruachan, a model may show up secondary phenomena which would otherwise have been overlooked or simply ignored because of the difficulty of reducing them to manageable mathematical expressions. A case in point was the phenomenon of translatory waves in the Cruachan surge galleries. The model studies showed this up very clearly, and led to the inclusion of the $30^{\circ}$ "beaches' at the ends of the galleries, shown in Fig. 8. Although a computer program could no doubt be devised to take account of these waves, this was not in fact done. This brings out the point that the computer cannot yet be said to have supplanted the hydraulic model in this field of study.

81. At Cruachan the computer was not used in the actual design of the surge shaft, but proved invaluable for checking the effect of the numerous combinations of operating procedures possible in a pumped storage station. It also proved its value during commissioning tests. Immediately after a test it was possible to do a computer run with the same input data and confirm that the surge shaft was in fact behaving as predicted. Fig. 11 illustrates typical results, which show satisfactory agreement as regards the primary surge. The secondary phenomenon of gallery 
surge is apparent from the irregularity of the test results at lowest downswing. The computer did not of course reproduce this, as it was not programmed to do so.

82. Even for its rather limited application in this case, the use of the computer was, I believe, clearly justified. The correlation of field tests with computer results not only gave increased confidence in the design of the actual surge shaft, but at the same time removed from my mind any doubts about the accuracy of the results which can be obtained from a computer in this type of problem. If Cruachan were being planned now instead of ten years ago, the computing techniques developed by Dr Matthew and Mr Robbie would certainly have been made use of at a very much earlier stage in the development of the surge shaft design.

\section{Dr Matthew and Mr Robbie}

We wish to thank the contributors for their valuable comments and for drawing attention to several inconsistencies. As several contributors noted, the title of Fig. 11 should have read:

Fig. 11. Sample results for three unit operation: (a) generation trip; (b) pump trip. Level in surge chamber is in $\mathrm{ft}$. OD.

We should also like to amend the value of $C$ given in $\S 45(b)$ from $9.22 \times 10^{-6}$ to $8 \cdot 10 \times 10^{-6}$.

84. Perhaps because of the title of the Paper, the impression appears to have been given that this method is in some way limited to mass oscillations in a pumped storage hydro-electric scheme. We should like to emphasize that the Heun-Romberg method, as described in $\$ \S 12-31$ and in the flow diagram of Fig. 2, is a general numerical method for the solution of a set of $n$ first-order differential equations with prescribed initial conditions. It is thus applicable to any physical problem which can be cast in this form, so that any mass oscillation problem falls within its scope. Furthermore, with the aid of finite-difference approximations for the spatial differential coefficients, the method could be applied to certain partial differential equations, such as the water hammer equations, as suggested by Dr Jaeger, or the transient open channel equations.

85. The generality of the method might also have been veiled by the dual purpose of the Paper, which set out

(a) to 'prove' a relatively untried numerical procedure;

(b) to get numerical results for an urgent engineering problem.

In a sense these aims were conflicting, in that $(a)$ required that the method be tested to its computational limits which, however, were considerably beyond the accuracy required, or even justified, by the uncertainties of the data used in $(b)$.

86. Mr Casinader reminds us of the traditionally used technique of carrying through the step-by-step computation, using, for example, the Heun procedure, over the complete range for which results are required. Successively smaller but constant step lengths are used, until an acceptable step length is established, which is neither too coarse to pick up the essential detail of the response yet not too fine, in which case numerical instability due to round-off could result. In the Heun-Romberg method, on the other hand, a fairly arbitrary choice of basic step length is made, and each of these basic steps is subdivided only sufficiently to maintain the specified accuracy (controlled by the tests described in $\S 30$ ). This process is thus dynamically self adjusting, so that in a rapidly varying region a fine subdivision will be made, while over a slowly varying region only coarse subdivision is necessary. This we feel has an inherent advantage over the method described by $\mathrm{Mr}$ Casinader, in which the constant step length employed would largely be governed by the region in which the variables are most rapidly varying. There may thus be no computational time advantage in an apparently simpler procedure. 
87. Mr Casinader gives a helpful résumé of the more common characteristics of pumped storage schemes, of which Cruachan is fairly typical, and rightly draws attention to the likelihood that the contributions made by the penstock and draft tube to inertia and friction might be more significant than in traditional hydro-electric configurations, where they are commonly neglected. We gave some thought to these factors, especially in relation to governing, whose inclusion simply increases the number of differential equations to be solved by the Heun-Romberg procedure.

88. Mr Casinader queries the discrepancy between the computed and observed initial peak in Fig. 11, case $(a)$. We believe that this is in part explained by the fact that, at that stage, we were using friction and other loss factors which were estimated, and not deduced from steady-state measurements on the actual installation (which were then unavailable). Another reason for the discrepancy is undoubtedly the complexity of flow between surge chamber and expansion gallery.

89. Mr Casinader and Mr Buchanan rightly imply that the treatment of an expansion gallery simply as an added horizontal area to the main surge chamber is an over-simplification, which ignores the wave propagation within the galleries and the possible existence of open channel controls at their junctions. At one time we contemplated a more thorough investigation of this on the digital computer, still using the Heun-Romberg method of integration, and approximating the partial differential equations for the flow in the galleries on the lines indicated in $\$ 84$. Since the galleries can operate either as open channels or under pressure, the formulation of the open channel equations suggested by Cunge and Wegner ${ }^{19}$ to cope with either condition was favoured.

90. Mr Evans is perfectly correct in assuming that the only factor which prevents equation (16) from being satisfied in reality is round-off error in the particular computational device used. Associated with this, the statement made in $\S 39(a)$ should have been qualified by a mention of the word length of the computer used, which for all the work described in the Paper was an Elliott 803 with 39-bit word length (29-bit mantissa). More recently some of these computations have been repeated on an English Electric System 4 which, with an Algol compiler, uses double precision arithmetic and has an effective word length of 64 bits (52-bit mantissa). As would be expected, this permits more extensive use of the simple Heun method, but still clearly brings out the vast improvement possible with the Heun-Romberg procedure.

91. Dr Jaeger has very correctly brought up the question of governor action, the introduction of which adds only very slightly to the difficulty of digital computation. We included this factor in some of the calculations to check on surge stability, but this was not reported in the Paper. To illustrate its inclusion in the scheme under study, the additional equation expressing constancy of power output on the generation phase is:

$$
\eta W Q_{\mathrm{D}}\left(H-Z-K_{\mathrm{D}} Q_{\mathrm{D}}^{2}+K_{\mathrm{s}} Q_{\mathrm{s}}\left|Q_{\mathrm{s}}\right|^{m-1}\right)=P \quad . \quad . \quad .
$$

where $\eta=$ turbine and generator efficiency

$W=$ specific weight of water, $1 \mathrm{bf} / \mathrm{cu}$. $\mathrm{ft}$

$H=$ gross head between upstream and downstream reservoirs, $\mathrm{ft}$

$K_{\mathrm{D}} Q_{\mathrm{D}}{ }^{2}=$ lumped friction and other losses in penstocks and draft tubes, $\mathrm{ft}$

$P=$ the (constant) power output for the particular governor setting, $l b f \mathrm{ft} / \mathrm{s}$.

It will be noted that here we are neglecting the inertia effects in the penstocks and draft tubes but allowing for the energy losses there. Let $P_{*}=$ power output under steady conditions at a discharge $Q$. with gross head of $H, \mathrm{lbf} \mathrm{ft} / \mathrm{s}$, and let $P=p P$., where $p$ is a pure number. By dividing throughout by $W Q * H$, equation (24) can be rendered dimensionless:

$$
\eta q_{\mathrm{D}}\left[1-\left(\frac{K_{\mathrm{D}} Q_{*}^{2}}{H}\right) q_{\mathrm{D}}^{2}-\left(\frac{Z *}{H}\right) z+\left(\frac{K_{\mathrm{S}} Q_{*}^{m}}{H}\right) q_{\mathrm{s}}\left|q_{\mathrm{s}}\right|^{m-1}\right]=\left(\frac{P_{*}}{W Q_{*} H}\right) p
$$

As a first approximation $\eta$ may be taken as constant, but on occasions its variation with load may have to be accounted for. 
92. Equation (24) in conjunction with equation (2a) thus provides a relationship between $q_{\mathrm{D}}$ and the main variables $q$ and $z$. The integration of equations (9) and (10) is carried out by the Heun-Romberg method and whenever required for function evaluation, equations (24a) and (2a) are solved iteratively to provide a $q_{\mathrm{D}}$ value.

93. With regard to the more complex problem of the interaction between the hydraulic and electrical distribution systems, we believe that a comprehensive and continuing study of this problem using both digital and analogue approaches is being made in the Department of Electrical Engineering in the University of Glasgow.

94. Finally, we agree with Mr Buchanan that there are still occasions on which the construction of a hydraulic model is warranted, especially when unusual geometrical features are present in the design. In such cases, we believe that parallel study on digital or analogue computers is highly desirable in order to check the validity of the mathematical models.

95. Once again we reiterate a plea for more hydraulic instrumentation on fullscale installations, so that direct comparison can be made between computed and measured results and more information can be gleaned on the validity of steady-state head loss expressions in transient conditions.

\section{References}

11. JAEGER C. A review of surge-tank criteria. J. bas. Engng, 1960, Dec., 765-783.

12. Streeter V. L. and WyLie E. B. Hydraulic transients. McGraw-Hill, 1967, Chap. 13.

13. Jaeger C. Théorie générale du Coup de Bélier. Dunod, Paris, 1933.

14. Marchal M. et al. The calculation of water hammer problems by means of the digital computer. International Symposium on Water Hammer in Pumped Storage Projects. American Society of Mechanical Engineers Meeting, Chicago, 7-11 November, 1965.

15. StreEter V. L. and WyLie E. B. Resonance in governed hydro-piping systems. International Symposium on Water Hammer in Pumped Storage Projects. American Society of Mechanical Engineers Meeting, Chicago, 7-11 November, 1965.

16. JAEGER C. Engineering fluid mechanics. Blackie and Sons, Glasgow, 1965.

17. JAEGER C. Contribution to the stability theory of systems of surge tanks. Trans. Am. Soc. mech. Engrs, 1958, 80, 1574-1584.

18. JAEGer C. The theory of resonance in hydro power systems. Trans. Am. Soc. mech. Engrs, 1963, 85 (Dec.) 631-640.

19. CUNGE J. A. and WEGNER M. Intégration numerique des équations d'écoulement de Barré de Saint-Venant par un schéma implicite de différence finies. Houille blanche, 1964 (1). 